Article

\title{
Real-Time Measurement on the Heat Release Property of Titanium Blended with Different Carbon Allotropes, under Externally Constant Heat Flux
}

\author{
Yachao Wang * $*$ and Jiangping Zhao \\ School of Resources Engineering, Xi'an University of Architecture \& Technology, Xi'an 710055, China \\ * Correspondence: wangyachao@xauat.edu.cn; Tel.: +86-29-8220-5869
}

Received: 23 July 2019; Accepted: 26 August 2019; Published: 4 September 2019

\begin{abstract}
Ti/C blended powder is commonly employed as an initiating combustion agent for preparing calcium aluminate; a dedicated test system is exploited for real-time examining of the heat release of Ti/C blended powder during combustion under atmosphere conditions with an externally constant heat flux of $973 \mathrm{~K}$, which is comprised of cone calorimeter, thermal-gravimetry/differential scanning calorimetry, X-ray diffraction (XRD), scanning electron microscope/energy dispersive spectrometer, and a theoretical thermal calculation, with the aim of quantitatively illuminating its combustion mechanism in depth. Furthermore, a comparison of the heat release property of titanium powder blended with different carbon allotropes, including natural flaky graphite (FG), carbon black (CB), expandable graphite (EG), and vermicular graphite (VG) is preliminarily investigated, to clarify the effect of different carbon allotropes on the heat release property of Ti/C blended powder. It reveals that the oxidation reaction between $\mathrm{Ti}$ and $\mathrm{O}_{2}$ initiates the subsequent combination of $\mathrm{TiC}$ through a thermal explosion reaction, using graphite (FG, VG, or EG) and Ti powder as the starting materials, respectively. Moreover, EG facilitates an accelerated (fire growth index of $0.42 \mathrm{~kW} \cdot \mathrm{m}^{-2} \cdot \mathrm{s}^{-1}$ ) and enhanced peak heat release rate (pHRR) of $30.7 \mathrm{~kW} \cdot \mathrm{m}^{-2}$ at $73 \mathrm{~s}$, while VG suppresses the heat release with the pHRR of $5.2 \mathrm{~kW} \cdot \mathrm{m}^{-2}$ at $64 \mathrm{~s}$ and fire growth index of $0.08 \mathrm{~kW} \cdot \mathrm{m}^{-2} \cdot \mathrm{s}^{-1}$, and FG favors the formation of $\mathrm{TiC}$ with a higher crystallinity from XRD. Additively, the prior $\mathrm{NaOH}$-impregnation is favorable for the formation of $\mathrm{TiC}$ for $\mathrm{Ti} / \mathrm{CB}$ blended powder, although the $\mathrm{TiO}_{2}$ predominates final combustion production. It reveals the chemical evolution and mechanisms evolved in the formation of TiC during ignition.
\end{abstract}

Keywords: titanium carbide; heat release properties; graphite; thermodynamic calculation; cone calorimeter; TG/DSC

\section{Introduction}

Titanium carbide $(\mathrm{TiC})$ is a good reinforcement for titanium matrix composites via self-propagating high-temperature synthesis (SHS), with many manifest advantages [1,2], due to its chemical compatibility with Ti, high hardness and Young's modulus, and high flexural strength [3], which is commercially produced by the overall reaction of $\mathrm{TiO}_{2}(\mathrm{~s})+\mathrm{C}(\mathrm{s})=\mathrm{TiC}(\mathrm{s})+2 \mathrm{CO}(\mathrm{g})$ under 1973-2373 K, using Ti powder and carbon black as the starting materials typically [4]. Simultaneously, the $\mathrm{Ti} / \mathrm{C}$ blended powder is commonly employed as the initiating combustion agent for preparing calcium aluminate via SHS [5,6]. Nevertheless, there is little literature on real-time testing of the heat release property during combustion of Ti/C blended powders, leading to the unclear chemical evolution and mechanisms evolved in reaction and growth of TiC both prior to, during, and after ignition [7].

In addition, the graphite or amorphous carbon black (CB) is mainly exploited as the carbon source for preparing $\mathrm{TiC}$ under an inert atmosphere [4,7-10]. The general consensus is that graphite 
contains expandable graphite (EG), vermicular graphite (VG), or expanded graphite after instantaneous expansion of EG, and natural flaky graphite (FG), which hold obviously different micro-structures and properties. Therefore, the various carbon sources affect the productions formed by SHS reaction [11]. It has been reported that the carbon nanotube and graphene as carbon sources impart enhanced tribological properties [12]; CB favors the formation of nano-metric TiC-carbon composite with a smaller particle size, as the most effective carbon allotrope for hindering the sintering of $\mathrm{TiC}$ under high temperature [13]. However, there is an interesting phenomenon-that the explosive reaction between graphite and titanium powder occurs under atmospheric pressure at $973 \mathrm{~K}$ with a transiently glaring flame, which inspired us to excavate its reaction mechanism, in order to explain the curious phenomenon.

Consequently, the real-time measurement of heat release property involved in titanium blended with different carbon allotropes is preliminarily investigated, which is detected and recorded by cone calorimeter (CC) and thermal-gravimetry/differential scanning calorimetry (TG/DSC), respectively, using FG, CB, EG, and VG as different carbon sources to react with titanium powder at an external heat flux of $973 \mathrm{~K}$. Meanwhile, the mercerization of different carbon allotropes by $\mathrm{NaOH}$-impregnation aims to investigate the effect of impurities involved in various carbon sources on the explosive reaction of Ti/C blended powders, due to that the impurities mainly belong to combustible organics within $\mathrm{CB}$, which are prone to transform into volatiles and disturb the solid-state reaction involved in Ti/C blended powders. Furthermore, the microstructure of reaction product is examined by X-ray diffraction (XRD) and scanning electron microscope (SEM), respectively. It aims to seek an effective avenue to deepen the reaction mechanism involved in the combustion of Ti/C blended powders. The novelty of this article is exploring an effectively quantitative method to clarify the mechanism of the period both prior to, and during combustion of Ti/C powder, using $\mathrm{Ti}$ and different carbon allotropes as the starting materials.

\section{Materials and Methods}

\subsection{Raw Materials}

The grey titanium powder was purchased from Tianjiu chemical group of Changsha in China, with an average particle size of $85 \mu \mathrm{m}$. Carbon allotropes, including EG with an average particle size of $320 \mu \mathrm{m}$ and a volume expansibility $400 \mathrm{~mL} \cdot \mathrm{g}^{-1}, \mathrm{CB}, \mathrm{VG}$, or FG with an average particle size of $85 \mu \mathrm{m}$, were all fabricated by Qingdao Tengsheng chemical group.

The XRD patterns of raw materials are presented in Figure 1; the hexagonal titanium (Ti, JCPDS 44-1294) is clearly detected. The graphite (C, JCPDS 41-1487) predominates the carbon allotropes, including FG, EG, and VG, but CB mainly consisted of the amorphous carbon (corresponding to the hump of $2 \theta$ at $15^{\circ}-30^{\circ}$ ).

The following samples denoted as S1-S9 were our research objectives: The S1 was neat Ti powder. The S2 was comprised of Ti and FG, S3 consisted of Ti and CB, S4 consisted of Ti and EG, and S5 consisted of Ti and VG. Additively, S6-S9 were the samples comprised of Ti and NaOH-impregnated carbon allotropes corresponding to S2-S5. And the $\mathrm{NaOH}$-impregnation was conducted by dispersing the carbon powder $(10 \mathrm{~g})$ into the $8 \mathrm{~mol} \mathrm{~L}^{-1} \mathrm{NaOH}(200 \mathrm{~mL})$ for $24 \mathrm{~h}$ under isolated air at room temperature; then the filter residue obtained by suction filtration was deionized water-washed to neutrality $(\mathrm{pH}=7)$; the final mercerized carbon allotropes were collected through vacuum drying at $333 \mathrm{~K}$. The FG-NaOH represented the FG subjected to $\mathrm{NaOH}$-impregnation, the EG-NaOH, CB-NaOH, and $\mathrm{VG}-\mathrm{NaOH}$ were assigned to the $\mathrm{EG}, \mathrm{CB}$, and $\mathrm{VG}$ after mercerization of $\mathrm{NaOH}$, respectively. The atomic molar ratio of Ti/C mixture equaled 1 in S2-S9 corresponding to a Ti/C weight rate of 4:1. The sample was subjected to a mechanically ball-grinding blending (15 min with a rotational speed of $100 \mathrm{rpm}$ at room temperature) before reaction in CC. 


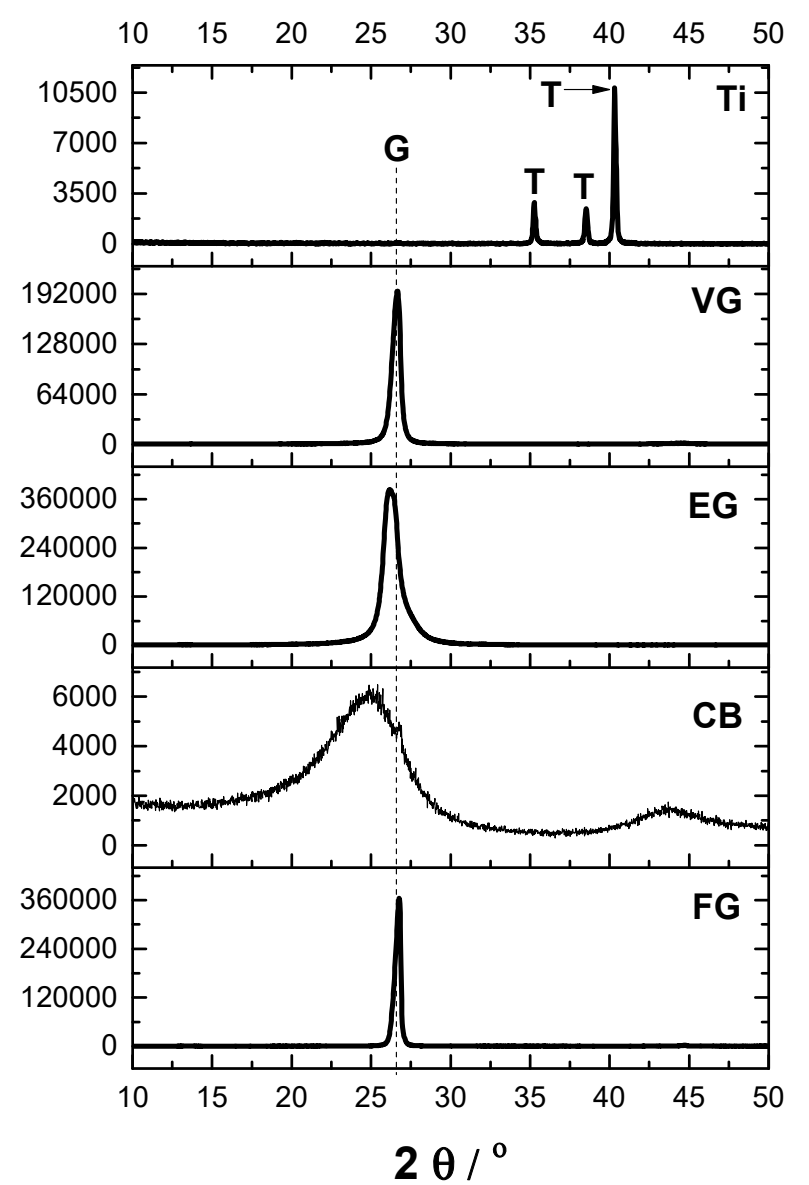

Figure 1. XRD of raw materials including titanium, flaky graphite (FG), carbon black (CB), expandable graphite (EG), and vermicular graphite (VG).

\subsection{Characterizations}

The real-time heat release rate (HRR) was examined by ZY6243 CC (Zhongnuo instrument company, Dongguan, China). The $12 \mathrm{~g}$ sample located on aluminum foil was placed horizontally to an external heat flux of $40 \mathrm{~kW} \cdot \mathrm{m}^{-2}$ ( $973 \mathrm{~K}$ approximately) for reactions with a vertical interval of $25 \mathrm{~mm}$. Simultaneously, the time to ignite (TTI), the peak heat release rate (pHRR), and the time to pHRR ( $\mathrm{t}_{\mathrm{p}}$ ) were automatic recorded. Total heat release (THR) was the cumulative heat release during the whole reaction except the external heat flux. The fire performance index (FPI) was defined as the ratio of TTI to $\mathrm{pHRR}(\mathrm{FPI}=\mathrm{TTI} / \mathrm{pHRR})$, and the fire growth index (FGI) was defined as the ratio of $\mathrm{pHRR}$ to $\mathrm{t}_{\mathrm{p}}$ $\left(F G I=p H R R / t_{p}\right)[14,15]$, which were important parameters to evaluate the heat release property.

A Mettler analyzer (Germany) was exploited to accomplish the TG/DSC analysis under the simulated atmosphere condition during the heating from 323 to $1273 \mathrm{~K}$ with a heating rate of $10 \mathrm{~K} \cdot \mathrm{min}^{-1}$. Microstructures of samples after reaction were characterized by Quanta 200 SEM, and D/MAX-2400 $\mathrm{X}$-ray diffractometer with $\mathrm{Cu} \mathrm{K} \alpha$ radiation, respectively.

\section{Results}

\subsection{HRR of Ti Blended with Different Carbon Allotropes}

The S5 comprised of VG and Ti presents the lowest $\mathrm{pHRR}$ value of $5.2 \mathrm{~kW} \cdot \mathrm{m}^{-2}$ among all Ti/C blended samples during the whole reaction, as shown in Figure 2a, due to the worm-like structure of VG, which traps and suppresses the transfer of heat and mass. S4, comprised of EG and Ti, exhibits the highest value $\left(30.7 \mathrm{~kW} \cdot \mathrm{m}^{-2}\right)$ of pHRR at $73 \mathrm{~s}$, due to the vigorous expansion of EG, which accelerates the propagation of combustion wave, prompting the heat and mass transfer. 


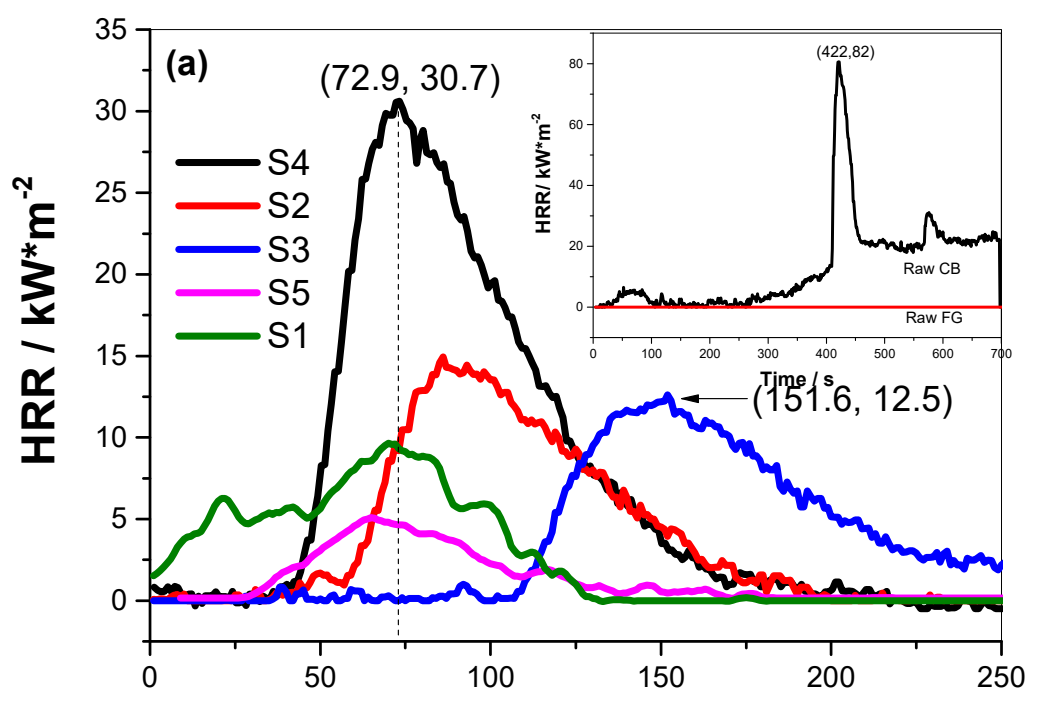

Time / s

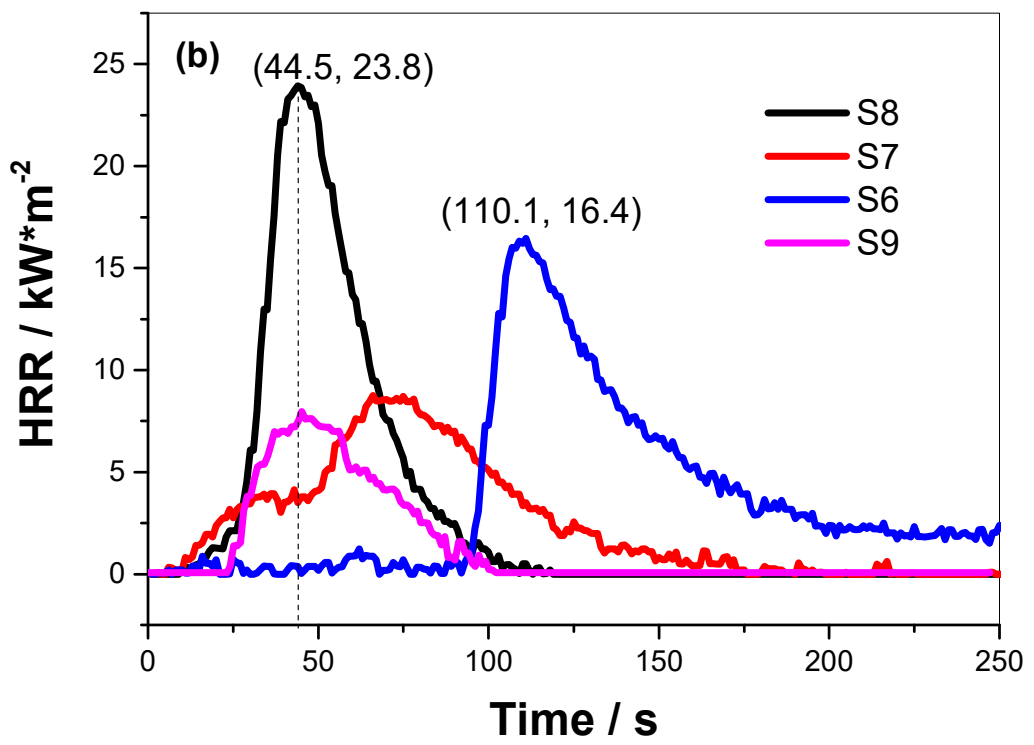

Figure 2. Hear release rate (HRR) of samples recorded by cone calorimeter (CC), including Ti/C blended powder before (a) and after (b) $\mathrm{NaOH}$ impregnation of carbon allotropes.

The $\mathrm{CB}$, owing to its high-activity and amorphousness, is prone to form a carbonaceous barrier to inhibit and dilute the heat under non-equilibrium, leading to the obviously retarding and shrunken peak with the pHRR value of $12.5 \mathrm{~kW} \cdot \mathrm{m}^{-2}$ at $152 \mathrm{~s}$. Furthermore, there is a sharp exothermic apex at $422 \mathrm{~s}$ corresponding to the combustion of raw $\mathrm{CB}$, as shown in Figure $2 \mathrm{a}$, while no peak is detected for the raw FG, indicating that pristine $\mathrm{CB}$ holds obvious and testable combustibility.

After $\mathrm{NaOH}$-impregnation of carbon allotropes, the shrunk and lower HRR curves are clearly examined for S7 and S8 compared with those of S3 and S4, as shown in Figure 2b, due to the impurities eliminated by $\mathrm{NaOH}$, leading to a remarkable increase in FGI, which rose from 0.08 to $0.12 \mathrm{~kW} \cdot \mathrm{m}^{-2} \cdot \mathrm{s}^{-1}$ for S3 (Table 1). However, the S6 exhibits a retarded $T_{p}$ with a decreased FGI compared with that of S2, due to the stable and inert structure of FG under the strong alkali-condition; it could have served as a heat dissipation filler, due to its high thermal conductivity [16].

Nevertheless, the increased pHRR and FGI are detected for S9 compared with that of S5, due to the subdued trapping effect of impurities after $\mathrm{NaOH}$-impregnation, leading to an earlier $\mathrm{T}_{\mathrm{p}}$. It is worth pointing that the $\mathrm{T}_{\mathrm{p}}$ of sample with $\mathrm{EG}$ or VG emerges at nearly the same time, because the prior heating 
makes the EG rapidly expand and transform into VG with worm-like structure at beginning of reaction. That is the same reactants present a similar reaction pathway except for the rapid expansion of EG.

Table 1. HRR properties of samples tested by CC.

\begin{tabular}{|c|c|c|c|c|c|c|c|}
\hline Samples & Ingredient & TTI/s & THR/kW & $\mathrm{pHRR} / \mathrm{kW} \cdot \mathrm{m}^{-2}$ & $\mathbf{T}_{\mathrm{p}} / \mathrm{s}$ & $\mathrm{FPI} / \mathrm{s} \cdot \mathrm{m}^{2} \cdot \mathrm{kW}^{-1}$ & $\mathrm{FGI} / \mathrm{kW} \cdot \mathrm{m}^{-2} \cdot \mathrm{s}^{-1}$ \\
\hline S1 & Pure Ti & 3 & 2.51 & 9.6 & 71.2 & 0.31 & 0.13 \\
\hline S2 & $\mathrm{Ti}+\mathrm{LP}$ & 16 & 8.77 & 14.9 & 85.5 & 1.07 & 0.17 \\
\hline S3 & $\mathrm{Ti}+\mathrm{CB}$ & 25 & 8.46 & 12.5 & 151.6 & 2.00 & 0.08 \\
\hline S4 & $\mathrm{Ti}+\mathrm{EG}$ & 2 & 17.19 & 30.7 & 72.9 & 0.07 & 0.42 \\
\hline S5 & $\mathrm{Ti}+\mathrm{VG}$ & 30 & 6.08 & 5.2 & 64.3 & 5.77 & 0.08 \\
\hline S6 & $\mathrm{Ti}+\mathrm{LP}-\mathrm{NaOH}$ & 28 & 8.11 & 16.4 & 110.1 & 1.71 & 0.15 \\
\hline S7 & $\mathrm{Ti}+\mathrm{CB}-\mathrm{NaOH}$ & 16 & 5.43 & 8.5 & 71.2 & 1.88 & 0.12 \\
\hline S8 & $\mathrm{Ti}+\mathrm{EG}-\mathrm{NaOH}$ & 2 & 7.01 & 23.8 & 44.5 & 0.08 & 0.53 \\
\hline S9 & $\mathrm{Ti}+\mathrm{VG}-\mathrm{NaOH}$ & 35 & 2.78 & 7.9 & 45.1 & 4.43 & 0.18 \\
\hline
\end{tabular}

Table 1 lists the heat-releasing parameters of samples, the S4 comprised of EG and Ti exhibits the highest FGI value of $0.42 \mathrm{~kW} \cdot \mathrm{m}^{-2} \cdot \mathrm{s}^{-1}$, while the S3 presents the lowest FGI of $0.08 \mathrm{~kW} \cdot \mathrm{m}^{-2} \cdot \mathrm{s}^{-1}$ (the same to that of S5), implying that the CB or VG inhibits the flame propagation effectively $[14,15]$. Because the EG transforms into fluffy worm-like structure with a vigorous expansion, it facilitates the propagation of combustion wave and heat transfer further due to the loose and fluffy stacking, which favors an extremely vigorous and energetic process [17], evidenced by the decrease in TTI and the rapid increase in HRR. However, the mercerization of $\mathrm{NaOH}$ favors the purification of carbon allotropes; the impurities could have transformed combustible volatiles and produced a higher heat release, evidenced by the decrease in the THRs for samples with carbons after $\mathrm{NaOH}$-impregnation. Meanwhile, they also transformed into char residues under the intensely heat-releasing condition, together with the traces of silicates, phosphates, and sulfates involved in EG or VG, which blocked or disturbed the solid-state reaction between activated $\mathrm{Ti}$ and carbon, leading to an obvious decrease in the THR. Because the sharp temperature-rising facilitates the formation of shielding char, it prevented further cracking of the pyrolysis products into non-condensable compounds [18].

\subsection{XRD of Samples after Reactions in CC}

The minerals contain khamrabaevite (TiC, JCPDS 32-1383, K) [19], tetragonal rutile ( $\mathrm{TiO}_{2}$, JCPDS 21-1276, R), orthorhombic titanium oxide ( $\mathrm{TiO}_{2}$, JCPDS 21-1236, T), and graphite (C, JCPDS 41-1487, G) are detected as shown in Figure 3. Pure Ti mainly transforms into titanium oxide and rutile. However, the coexistence of predominant $\mathrm{TiC}$ and a slight $\mathrm{TiO}_{2}$ was confirmed for samples with FG, EG or VG, revealing that the formation of $\mathrm{TiC}$ is feasible under atmospheric conditions at $973 \mathrm{~K}$, and the sharper and narrower peaks are attributed to the $\mathrm{TiC}$ with a higher crystallinity [20]. Meanwhile, a small quantity of rutile is formed and some graphite left, which clearly determines that the off-stoichiometric reaction occurs between $\mathrm{Ti}$ and graphite, due to the non-equilibrium condition and the dominated slow solid-state reaction. On the contrary, the sample S3 comprised of CB and Ti mainly presents the peaks corresponding to $\mathrm{TiO}_{2}$ and rutile; the hump of $2 \theta$ at $25^{\circ}-28^{\circ}$ assigned to amorphous graphite was recorded, and implies that complicated reactions occur, which will be discussed later.

Additively, some interesting phenomena are observed in the patterns of XRD after the $\mathrm{NaOH}$-impregnation of carbon allotropes, as shown in Figure 4. The sharper peaks corresponding to TiC with a higher crystallinity are detected for S6 and S8 respectively, compared with those of S2 and $\mathrm{S} 4$ in Figure $4 \mathrm{a}, \mathrm{b}$, which indicates that the $\mathrm{NaOH}$-impregnation favors the formation of TiC through the direct solid-state reaction between $\mathrm{Ti}$ and $\mathrm{C}$ at $973 \mathrm{~K}$.

The $\mathrm{NaOH}$ could eliminate the impurities involved in various carbon sources, which hinder or disturb the solid-state reaction. Meanwhile, the shrunk peaks corresponding to graphite are observed in the pattern of S7; the sharper peaks corresponding to $\mathrm{TiO}_{2}$ and the small peaks corresponding to $\mathrm{TiC}$ emerge in Figure 4c. When compared with those of S3, they reveal that the pre-treatment of CB by $\mathrm{NaOH}$-impregnation affects the reactions significantly. 


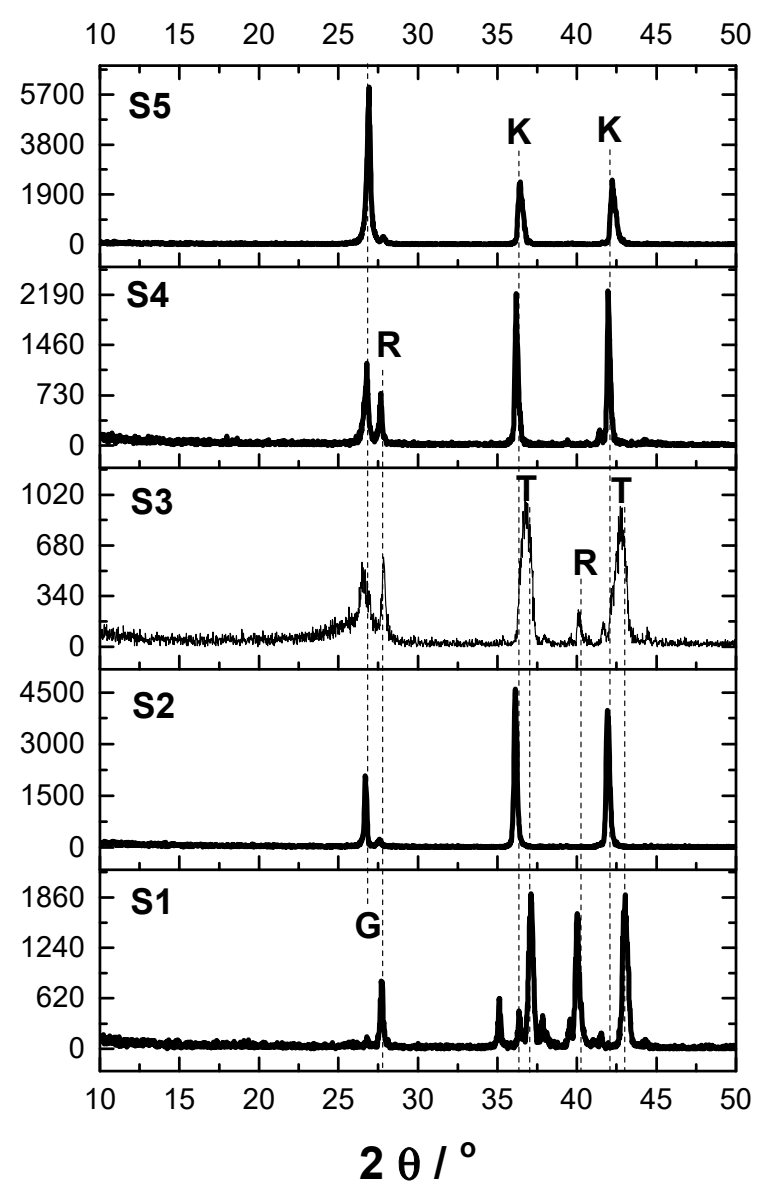

Figure 3. $\mathrm{XRD}$ of $\mathrm{Ti} / \mathrm{C}$ samples after reactions in $\mathrm{CC}$. $\mathrm{K}$-khamrabaevite, $\mathrm{R}$-rutile, $\mathrm{T}$-titanium oxide, and G-graphite.

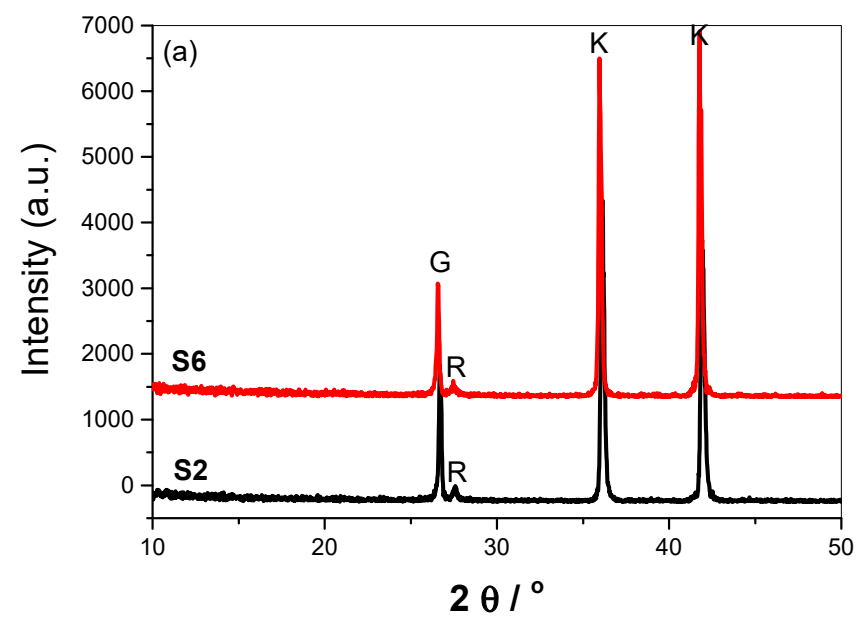

Figure 4. Cont. 

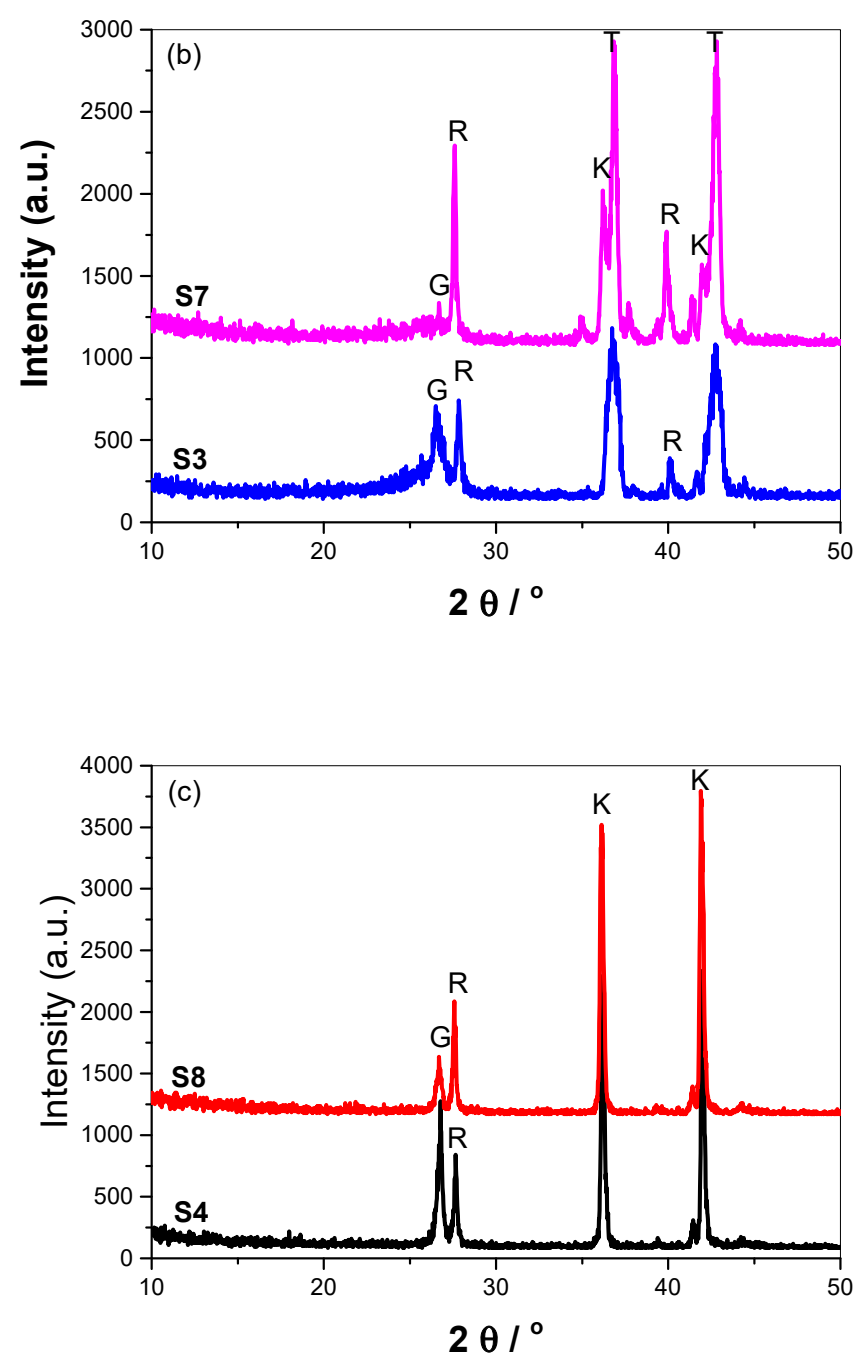

Figure 4. Comparative patterns of $\mathrm{Ti} / \mathrm{C}$ blended powder before and after $\mathrm{NaOH}$ impregnation of carbon allotropes including (a) Ti/FG, (b) Ti/CB, and (c) Ti/EG. K-khamrabaevite, R-rutile, T-titanium oxide, and G-graphite.

Generally, the solid-state reaction of TiC-forming occurs, and the prior NaOH-impregnation of carbon allotropes promote and strengthen the reaction. Moreover, it is suspected that the reactions involved in Ti/C blended powder mainly contain the following Equations (1)-(8), and the thermodynamic data including enthalpy $\Delta H$ and Gibbs free energy $\Delta G$ is briefed in Table 2, which is clarified later.

$$
\begin{gathered}
\mathrm{Ti}+\mathrm{O}_{2}(\mathrm{~g})=\mathrm{TiO}_{2} \\
\mathrm{Ti}+\mathrm{C}=\mathrm{TiC} \\
\mathrm{TiO}_{2}+\mathrm{C}=\mathrm{Ti}+\mathrm{CO}_{2}(\mathrm{~g}) \\
\mathrm{TiO}_{2}+2 \mathrm{C}=\mathrm{TiC}+3 \mathrm{CO}_{2}(\mathrm{~g}) \\
\mathrm{TiO}_{2}+3 \mathrm{C}=\mathrm{TiC}+3 \mathrm{CO}(\mathrm{g}) \\
2 / 3 \mathrm{CO}(\mathrm{g})+\mathrm{Ti}=2 / 3 \mathrm{TiC}+1 / 3 \mathrm{TiO}_{2} \\
\mathrm{TiC}+2 \mathrm{O}_{2}(\mathrm{~g})=\mathrm{TiO}_{2}+\mathrm{CO}_{2}(\mathrm{~g}) \\
\mathrm{TiC}+1.5 \mathrm{O}_{2}(\mathrm{~g})=\mathrm{TiO}_{2}+\mathrm{CO}(\mathrm{g})
\end{gathered}
$$


Table 2. Thermodynamic data of reactions.

\begin{tabular}{|c|c|c|c|c|c|c|c|c|}
\hline \multirow{2}{*}{$\mathbf{T} / \mathbf{K}$} & \multicolumn{2}{|c|}{ Equation (1)/kJ $\times \mathrm{mol}^{-1}$} & \multicolumn{2}{|c|}{ Equation (2)/kJ $\times \mathrm{mol}^{-1}$} & \multicolumn{2}{|c|}{ Equation (3)/kJ $\times \mathrm{mol}^{-1}$} & \multicolumn{2}{|c|}{ Equation (4)/kJ $\times \mathrm{mol}^{-1}$} \\
\hline & $\Delta \mathbf{H}$ & $\Delta \mathrm{G}$ & $\Delta \mathbf{H}$ & $\Delta \mathrm{G}$ & $\Delta \mathbf{H}$ & $\Delta \mathrm{G}$ & $\Delta \mathbf{H}$ & $\Delta \mathrm{G}$ \\
\hline 273 & -1154.3 & -1107.7 & -184.6 & -181.2 & 551.5 & 500.0 & 366.9 & 318.8 \\
\hline 373 & -1154.3 & -1090.7 & -184.4 & -180.0 & 551.2 & 481.2 & 366.8 & 301.1 \\
\hline 473 & -1153.9 & -1073.7 & -184.1 & -178.9 & 550.4 & 462.5 & 366.3 & 283.6 \\
\hline 573 & -1153.4 & -1056.8 & -183.8 & -177.8 & 549.4 & 444.0 & 365.5 & 266.2 \\
\hline 673 & -1152.8 & -1039.9 & -183.7 & -176.8 & 548.2 & 425.7 & 364.6 & 248.9 \\
\hline 773 & -1152.1 & -1023.2 & -183.7 & -175.8 & 547.1 & 407.6 & 363.5 & 231.8 \\
\hline 873 & -1151.3 & -1006.6 & -183.8 & -174.7 & 546.1 & 389.6 & 362.3 & 214.9 \\
\hline 973 & -1150.6 & -990.1 & -183.9 & -173.7 & 545.0 & 371.8 & 361.1 & 198.1 \\
\hline 1073 & -1149.8 & -973.6 & -184.3 & -172.6 & 544.2 & 354.0 & 359.9 & 181.4 \\
\hline 1173 & -1148.9 & -957.3 & -189.4 & -171.4 & 548.0 & 336.2 & 358.6 & 164.8 \\
\hline 1273 & -1148.1 & -941.0 & -189.2 & -169.9 & 546.6 & 318.3 & 357.4 & 148.3 \\
\hline \multirow{2}{*}{$\mathbf{T} / \mathbf{K}$} & \multicolumn{2}{|c|}{ Equation (5)/kJ $\times \mathrm{mol}^{-1}$} & \multicolumn{2}{|c|}{ Equation (6)/kJ $\times \mathrm{mol}^{-1}$} & \multicolumn{2}{|c|}{ Equation (7)/kJ $\times \mathrm{mol}^{-1}$} & \multicolumn{2}{|c|}{ Equation (8)/kJ $\times \mathrm{mol}^{-1}$} \\
\hline & $\Delta \mathbf{H}$ & $\Delta \mathrm{G}$ & $\Delta \mathbf{H}$ & $\Delta \mathrm{G}$ & $\Delta \mathbf{H}$ & $\Delta \mathrm{G}$ & $\Delta \mathbf{H}$ & $\Delta \mathrm{G}$ \\
\hline 273 & 539.1 & 443.2 & -364.3 & -329.0 & -1154.3 & -1107.7 & -871.4 & -848.3 \\
\hline 373 & 540.0 & 407.9 & -364.4 & -316.0 & -1154.3 & -1090.7 & -870.8 & -839.9 \\
\hline 473 & 539.9 & 372.5 & -364.1 & -303.1 & -1153.9 & -1073.7 & -870.2 & -831.7 \\
\hline 573 & 539.1 & 337.2 & -363.5 & -290.2 & -1153.4 & -1056.8 & -869.6 & -823.6 \\
\hline 673 & 537.8 & 302.1 & -363.0 & -277.5 & -1152.8 & -1039.9 & -869.1 & -815.6 \\
\hline 773 & 536.1 & 267.2 & -362.4 & -264.8 & -1152.1 & -1023.2 & -868.6 & -807.7 \\
\hline 873 & 534.1 & 232.5 & -361.8 & -252.2 & -1151.3 & -1006.6 & -868.2 & -799.9 \\
\hline 973 & 532.0 & 198.1 & -361.3 & -239.7 & -1150.6 & -990.1 & -867.7 & -792.1 \\
\hline 1073 & 529.8 & 163.8 & -361.0 & -227.3 & -1149.8 & -973.6 & -867.3 & -784.3 \\
\hline 1173 & 527.6 & 129.8 & -365.2 & -214.7 & -1148.9 & -957.3 & -866.9 & -776.6 \\
\hline 1273 & 525.2 & 96.0 & -364.3 & -201.9 & -1148.1 & -941.0 & -866.5 & -769.0 \\
\hline
\end{tabular}

\subsection{TG/DSC of Samples}

Figure 5a presents a single peak in DTG corresponding to the formation of $\mathrm{TiO}_{2}$ according to the result of XRD, leading to an exothermic peak at $1047 \mathrm{~K}$ with a heat release of $19.1 \mathrm{~kJ} \cdot \mathrm{g}^{-1}$ and a sharp weight increase of $164 \%$, and the theoretical enthalpy and weight increments are about $19.5 \mathrm{~kJ} \cdot \mathrm{g}^{-1}$ and $167 \%$ for the $\mathrm{Ti}$ completely transforms into $\mathrm{TiO}_{2}$ as Equation (1), which indirectly reveal that there is some unreacted Ti, evidenced by the pattern of XRD. And the temperature corresponding to DTG $_{\max }$ is $1053 \mathrm{~K}$ with an initial weight increase temperature of $950 \mathrm{~K}$, which is mainly assigned to the formation of $\mathrm{TiO}_{2}$.

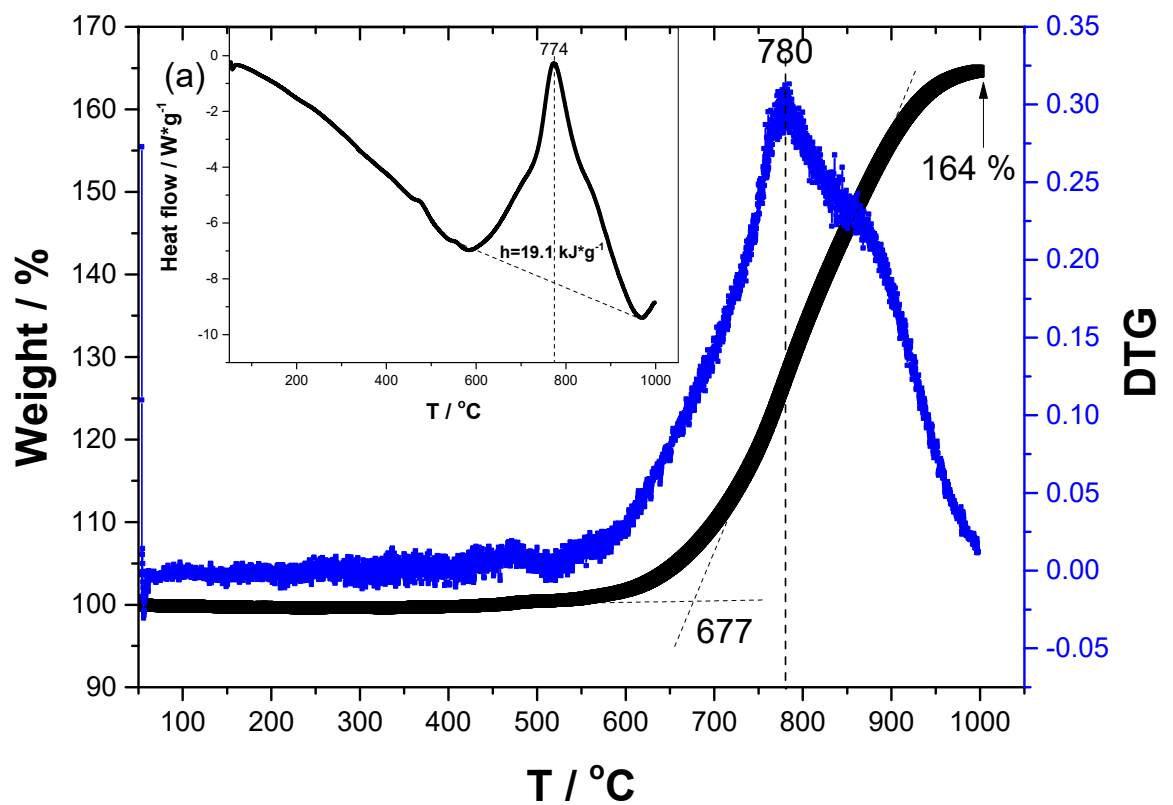

Figure 5. Cont. 

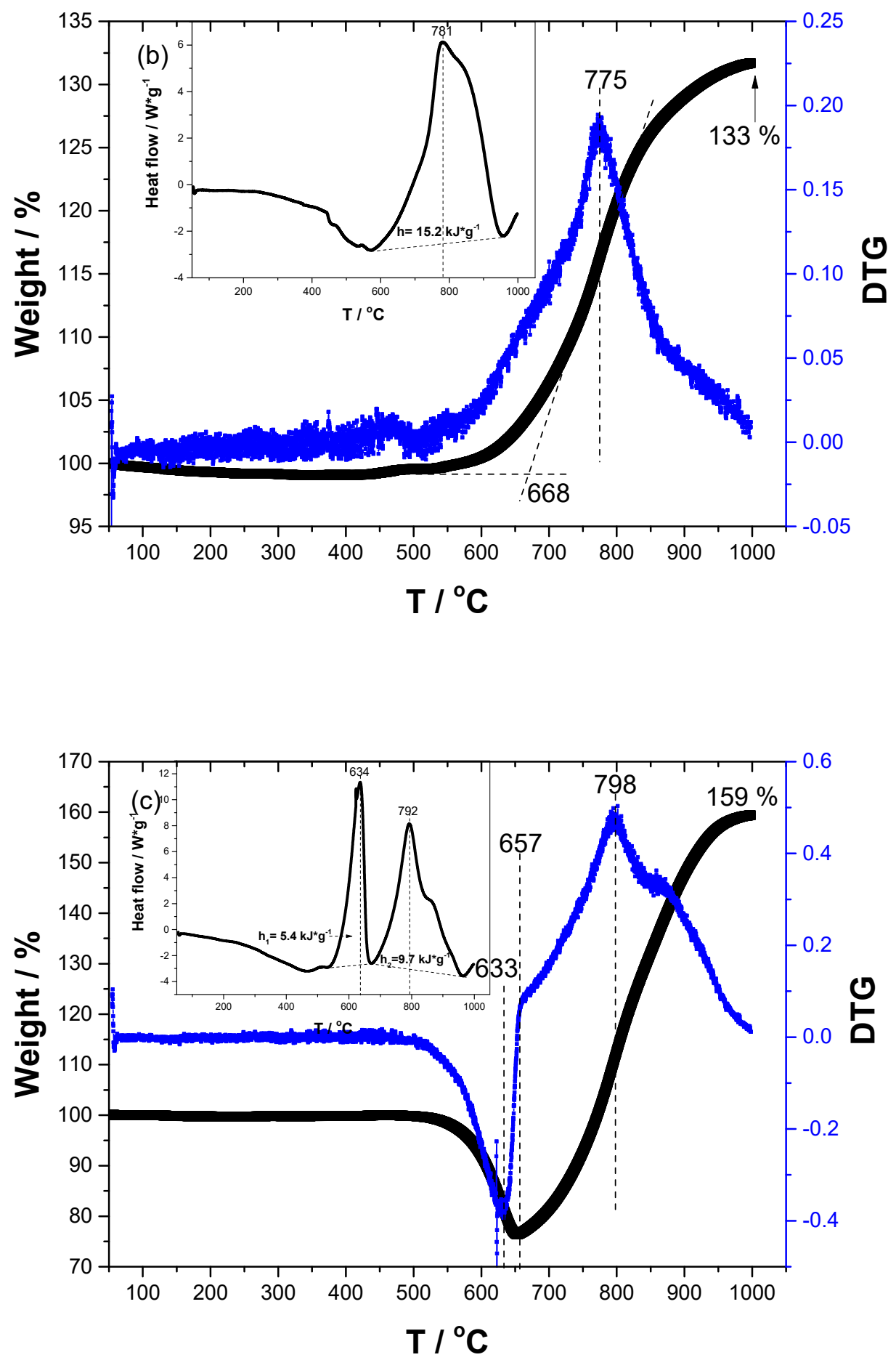

Figure 5. Cont. 


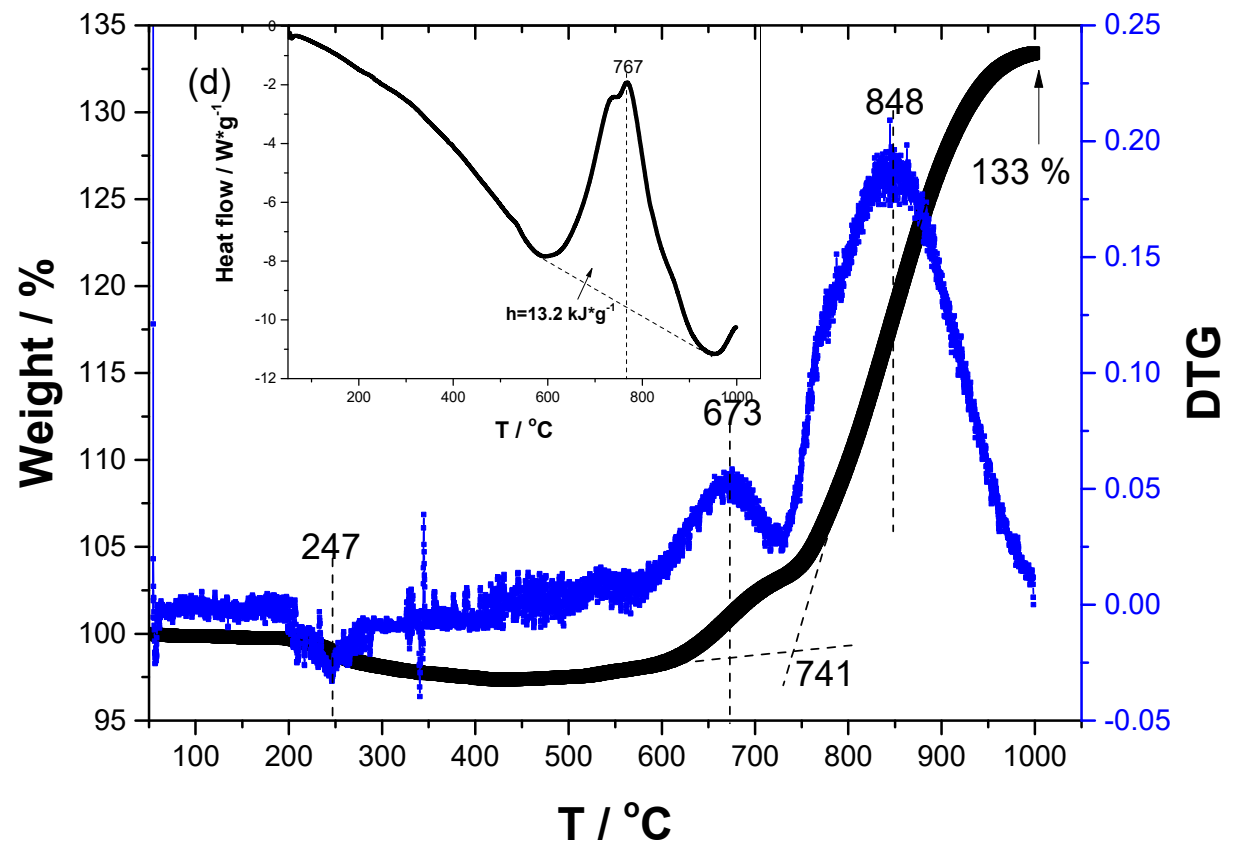

Figure 5. Thermal-gravimetry/differential scanning calorimetry (TG/DSC) of samples, including (a) S1, (b) S2, (c) S3, and (d) S4.

According to the theoretically chemical calculation for the Ti/C blended powder, the theoretical enthalpies for Equations (2) and (6) are $15.6 \mathrm{~kJ} \cdot \mathrm{g}^{-1}$ and $6.0 \mathrm{~kJ} \cdot \mathrm{g}^{-1}$, and the weight increases are $35 \%$ and $22 \%$, respectively. It is worth pointing that the S2 and S4 exhibit the same final weight of $133 \%$, as shown in Figure 5b,d, indicating that the formation of TiC occurs predominantly. Nevertheless, S3 presents first, a weight loss, and subsequently, a weight increase with a final weight of $159 \%$, taking on two exothermic peaks at $907 \mathrm{~K}$ and $1065 \mathrm{~K}$ in Figure 5c. The former is attributed to the oxidization of combustible hydrogen, carbon, and other impurities within CB [21], leading to a continuous weight loss with a peak valley at $930 \mathrm{~K}$. The latter is mainly attributed to the formation of $\mathrm{TiO}_{2}$, leading to a rapid weight increase combining with the results of XRD.

However, a slight weight loss at $520 \mathrm{~K}$ corresponding to the expansion of EG is recorded for S4, and the exothermic peak $\left(13.2 \mathrm{~kJ} \cdot \mathrm{g}^{-1}\right)$ at $1040 \mathrm{~K}$ is weaker than others in Figure $4 \mathrm{~d}$, due to the endothermic transformation from EG to VG. Two obvious DTG $\max$ at 946 and $1121 \mathrm{~K}$ are observed, with an initial weight increase temperature of $1014 \mathrm{~K}$, implying a retarding effect involved in the formation of $\mathrm{TiO}_{2}$ and $\mathrm{TiC}$, ascribed to barrier effect of worm-like graphite [13].

\subsection{Morphologies of Samples after Reaction in CC}

\subsubsection{Macro-Appearances of Samples after Reactions}

The pure Ti is mainly transformed into a yellow-white solid, as shown in Figure 6a, corresponding to the $\mathrm{TiO}_{2}$. As for the $\mathrm{S} 2$ comprised of $\mathrm{FG}$ and $\mathrm{Ti}$, the non-uniform morphology identifies an incomplete reaction in Figure $6 \mathrm{~b}$. When the $\mathrm{CB}$ is used as the starting material, a higher content of yellow-white solid is observed in Figure 6c. Additively, the fluffy worm-like graphite covers the underlying solid in Figure $6 \mathrm{~d}$, implying that a vigorous expansion occurs during the reaction. But the brownish black powder (similar to the mixture without reaction) is observed in Figure 6e, due to the under-reacting combination.

S6, S7, and S8 (Figure 7a-c) exhibit similar appearances in comparison to that of S2-S4, but S9 takes on an obviously different appearance compared with that of S5. The yellow and black solids (in Figure 7d) reveal that the $\mathrm{NaOH}$-impregnation plays a crucial role in the reaction of Ti/VG powders, compared with the brownish black appearance for S5. 


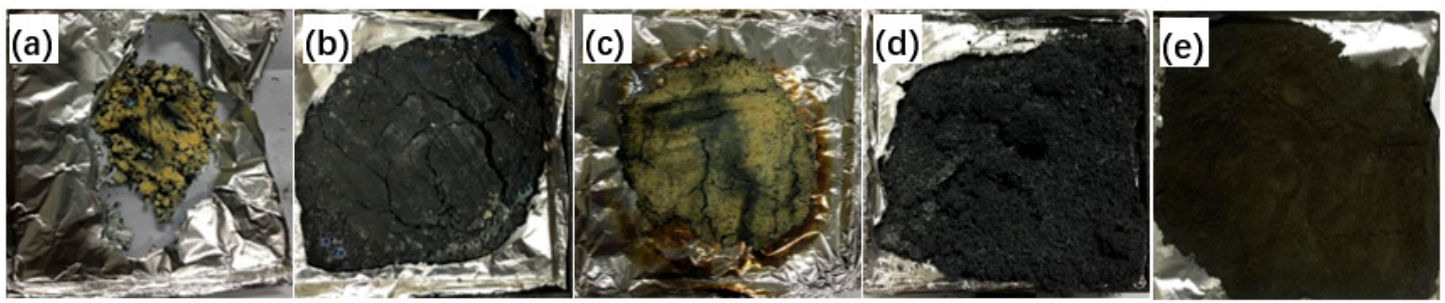

Figure 6. Macro-appearances of samples without $\mathrm{NaOH}$ impregnation after reactions in $\mathrm{CC}$, including (a) S1, (b) S2, (c) S3, (d) S4, and (e) S5.
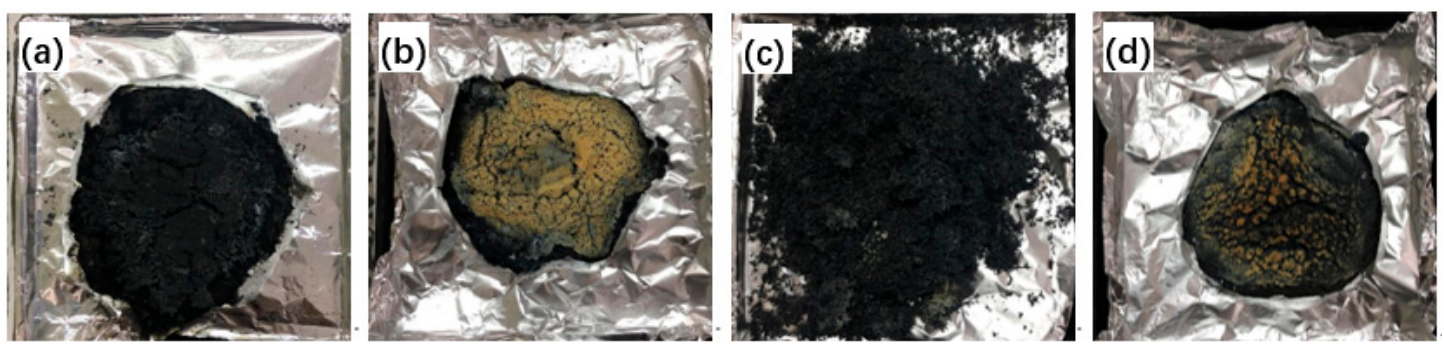

Figure 7. Macro-appearances of samples subjected to $\mathrm{NaOH}$-impregnation after reactions in $\mathrm{CC}$ including (a) S6, (b) S7, (c) S8 and (d) S9.

\subsubsection{Micro-Morphologies of Samples after Reaction}

The irregular pillared-rutile is observed in Figure $8 \mathrm{a}$, and the amorphous TiC covered on the underlying matrix is observed in Figure 8b, which consists of polyhedral grains intimately fused with clean grain boundaries [22,23]. However, the lower regularity of rutile is observed than that of S1, and lots of amorphous graphite particles are dispersed in the clearances of $\mathrm{TiO}_{2}$ in Figure $8 \mathrm{c}$, due to the insufficient time derived from the non-equilibrium condition and barrier effect of $C B$ [24]. The porous and fluffy worm-like graphite mixed with the TiC appears in Figure 8d, and more dissociated and rugged fracture surface is observed in Figure 8e, due to the retarding effect of worm-like structures. Generally, the formation of $\mathrm{TiC}$ is examined and verified, but the high retained porosity is observed owing to its inherent limitation of combustion synthesis [25].

After $\mathrm{NaOH}$-impregnation of carbon allotropes, the continuous and uniform fracture surface is observed in Figure 9, because the mercerization is beneficial to remove the impurities and make the inert char residues decrease, which indirectly accelerates the solid-state reaction between Ti and C, as well as the reaction between $\mathrm{Ti}$ and $\mathrm{O}_{2}$, leading to the appearance of $\mathrm{TiC}$ with a higher crystallinity in Figure 9a. The unreacted graphite is absent in Figure $9 \mathrm{~b}$ in comparison to that in Figure $8 c$, and the $\mathrm{TiO}_{2}$ is mainly the reaction production. Furthermore, the smooth and uniform appearances in Figure $9 \mathrm{c}$ are assigned to the fluffy graphite lamellar; the TiC disperses or inserts into the interstitial lamellar. While the bigger particles emerge for S9 (in Figure 9d) than that of S5 (in Figure 8e), due to the enhanced solid-state reaction including formations of $\mathrm{TiC}$ and $\mathrm{TiO}_{2}$. 

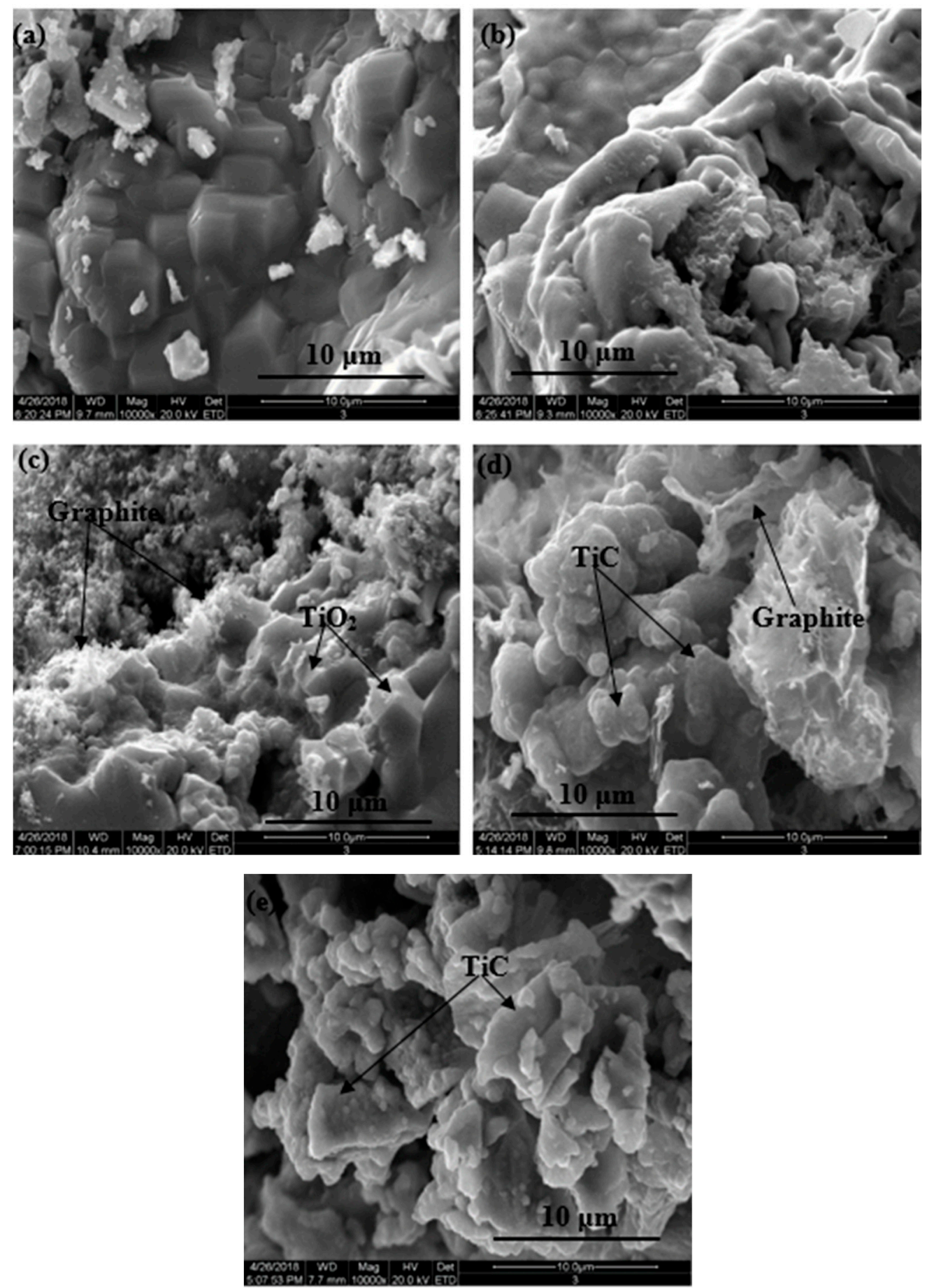

Figure 8. SEM of samples after reactions in CC (10,000 × magnification), including (a) S1, (b) S2, (c) S3, (d) S4, and (e) S5. 

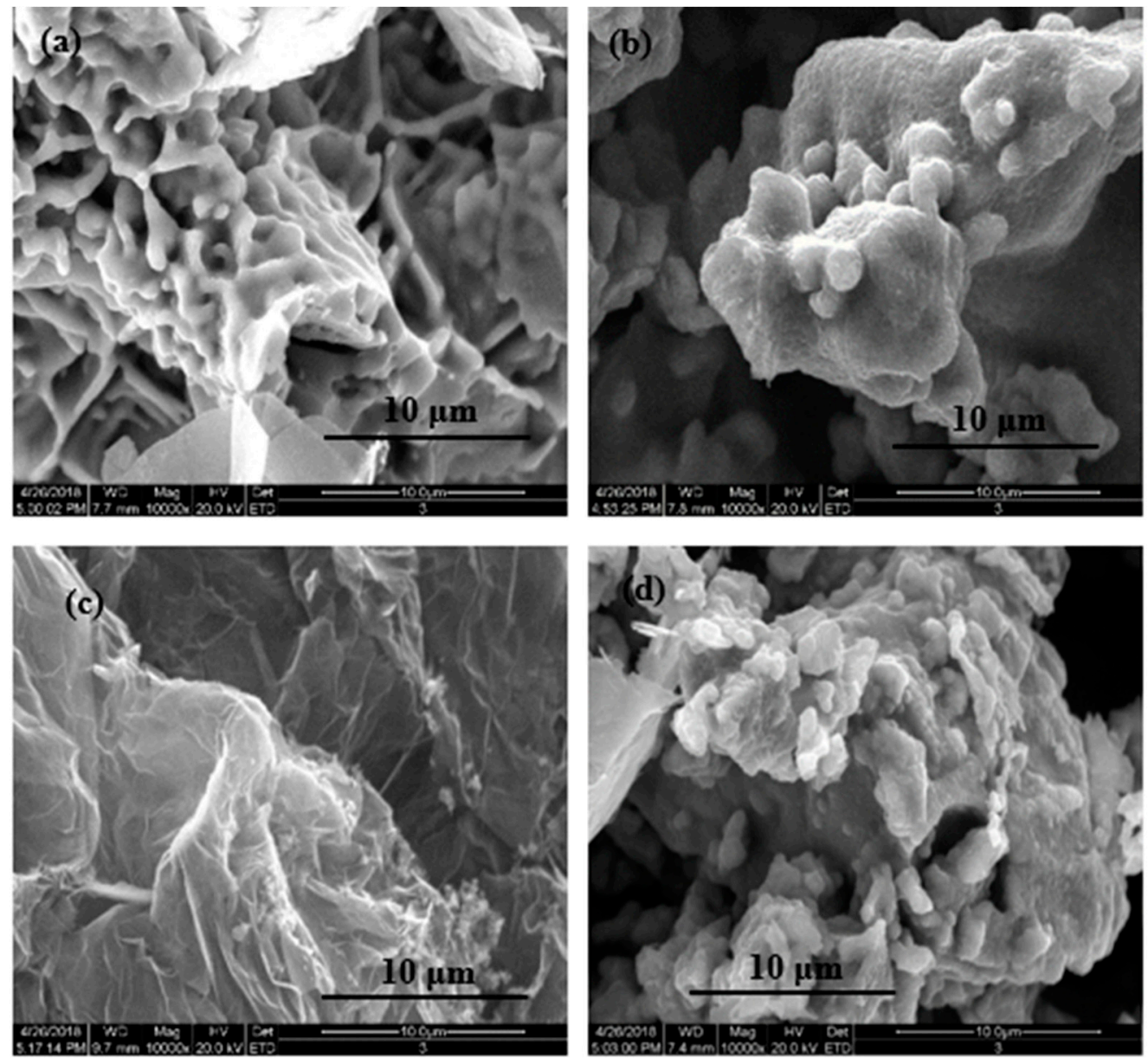

Figure 9. SEM of samples subjected to $\mathrm{NaOH}$-impregnation after reactions in $\mathrm{CC}(10,000 \times$ magnification), including (a) S6, (b) S7, (c) S8 and (d) S9.

\section{Discussion}

The discrepancy between the results of CC and DSC was discovered, obviously. S3 comprised of Ti and CB exhibits the lowest pHRR value and the highest value of heat release tested by DSC, while the S4 comprised of Ti and EG exhibits the highest value of pHRR and the lowest heat release tested by DSC. Because the radiation cone in CC was heated to $973 \mathrm{~K}$ prior to measurement, the EG expanded quickly and transformed into fluffy and loose-stacked powder from the beginning of reaction; together with the non-equilibrium condition derived from the extremely rapid heat release, they provide the suddenly increased pathways for the diffusion of $\mathrm{O}_{2}$, and accelerate the combination of $\mathrm{Ti}, \mathrm{O}_{2}$, and graphite, leading to the enhancement of HRR. Nevertheless, the slow-heating DSC provides a uniform and sufficiently equilibrated condition for the reaction, leading to a step-by-step reaction and a complete combination. The combustible materials in $\mathrm{CB}$ carbonizes and transforms into non-combustible char residues, which inhibits the flame propagation and dilutes the reactants, leading to a sharply reduced HRR, evidenced by the two obvious exothermic peaks in DSC curve. Zhu et al. [26] also found that delaying flammability caused a reduced HRR with an enhanced heat release.

On the other hand, the prior oxidation of Ti releases the heat (reaching $2513 \mathrm{~K}$ ) under atmospheric conditions [27], which promotes the thermal explosion reaction between the Ti and C powders due to the chemical oven mechanism, leading to the formation of TiC. According to the literature [28,29], the dissolution-precipitation mechanism mainly governs the formation of $\mathrm{TiC}$, whereas the diffusion of carbon to the Ti molten liquid is the prerequisite. But the insufficient time limits the completion of the dissolution and diffusion processes; the intensely releasing heat disturbs the formation of a continuous carbide layer around the Ti particle during the thermal explosion reaction [29] 
However, TiC could also be synthesized by mechanical milling [30], or by rapid combustion-type behavior at $873 \mathrm{~K}$ [31]. Consequently, the reaction-diffusion mechanism involved in the formation of $\mathrm{TiC}$ at atmosphere condition with an externally constant heat flux of $973 \mathrm{~K}$ could be elaborated as the following processes, combining with the thermodynamic calculation. The pure Ti mainly reacts with the $\mathrm{O}_{2}$ derived from air, as in Equation (1), and transforms into rutile and $\mathrm{TiO}_{2}$ with a sharp increase in the weight, but the coexistence of $\mathrm{TiO}_{2}$ and $\mathrm{Ti}$ was detected due to the non-equilibrium condition derived from the extremely rapid heat release. Meanwhile, the diffusion of carbon towards the surfaces of $\mathrm{TiO}_{2}$ and Ti occurs, which provides the formation condition for $\mathrm{TiC}$, together with the intensively releasing heat, led to the explosive reactions with a transiently glaring flame. Additively, the expansion of EG favors the surface reactions between $\mathrm{O}_{2}$ and Ti [32]. The formation of $\mathrm{TiO}_{2}$ (Equation (1)) is easier than that of TiC (Equation (2)), evidenced by the higher enthalpy in Table 2, and the formation of $\mathrm{TiO}_{2}$ releases a higher heat amount for subsequent combination of $\mathrm{TiC}$, leading to the obviously enhanced characteristic peaks corresponding to TiC. Besides, the subsequent reduction reaction between $\mathrm{CO}$ (derived from the transformation of impurities in CB) and Ti left preferentially occurs, as in Equation (6), due to the higher Gibbs enthalpy (Equations (3)-(5)) not occurring (due to their positive $\Delta \mathrm{Gs}$ ), which is completely consistent with the literature [33,34]. But the oxidation of $\mathrm{TiC}$ takes place as Equation (8), due to the higher $\Delta \mathrm{H}$ and $\Delta \mathrm{G}$ than that of Equation (7) above $973 \mathrm{~K}$, leading to the absence of TiC for $\mathrm{S} 3$. However, the $\mathrm{NaOH}$-impregnation causes the appearance of $\mathrm{TiC}$, which might be contributed to the low THR of S7 (5.43 kW compared with $8.46 \mathrm{~kW}$ of S3) limiting the oxidation of Equation (8), leading to slight TiC content remaining.

The solid-state reaction between FG and $\mathrm{Ti}$ is beneficial towards forming the $\mathrm{TiC}$, but the quantitative research and mechanical performance of the synthesized $\mathrm{TiC}$ need to be studied further, and the modification on its micro-structure holds great potential in our future research, including the interface characteristics among the $\mathrm{TiC}$, rutile, and graphite.

\section{Conclusions}

Ti/C blended powder is commonly employed as initiating combustion agent for preparing novel calcium aluminate cement, but the heat release of $\mathrm{Ti} / \mathrm{C}$ blended powder during the whole reaction has not been explored yet. Therefore, an effective and comprehensive test system was used to real-timely examine the heat release of reaction within Ti/C blended powder under atmospheric conditions, with an externally constant heat flux of $973 \mathrm{~K}$, containing the techniques CC, TG/DSC, XRD, and SEM, providing necessary data to deepen the reaction mechanism. To quantitatively illuminate its combustion mechanism further, a comparison on the heat release of titanium with different carbon allotropes (FG, EG, VG, and CB) was preliminarily investigated. The rapid expansion of EG accelerates the $\mathrm{O}_{2}$ diffusion and heat-transfer, and intensifies the non-equilibrium condition, leading to the accelerated and enhanced pHRR of $30.7 \mathrm{~kW} \cdot \mathrm{m}^{-2}$ at $73 \mathrm{~s}$. However, the CB enriched amorphous impurities mainly transforms into $\mathrm{TiO}_{2}$, which traps the volatiles and retards the transfer of heat/mass effectively, leading to an obvious barrier effect under the non-equilibrium condition, evidenced by the pHRR of $12.5 \mathrm{~kW} \cdot \mathrm{m}^{-2}$ at $152 \mathrm{~s}$. FG and VG favors the formation of TiC with a higher crystallinity, and the prior $\mathrm{NaOH}$-impregnation plays a negligible role in the combination of $\mathrm{TiC}$ for Ti/FG blended powder, apart from the formation of TiC with a higher crystallinity, as well as for the Ti/EG and Ti/VG blended powders. Additively, the $\mathrm{NaOH}$-impregnation is favorable for the formation of $\mathrm{TiC}$ for $\mathrm{Ti} / \mathrm{CB}$ blended powder. The theoretically thermal calculations demonstrate that the heat release derived from the oxidation reaction between $\mathrm{Ti}$ and $\mathrm{O}_{2}$ initiates the combination of $\mathrm{TiC}$ through thermal explosion reaction, and the subsequent oxidation reaction between $\mathrm{TiC}$ and $\mathrm{O}_{2}$ also occurs slightly.

Author Contributions: Conceptualization, Y.W. and J.Z.; Methodology, Y.W.; Validation, Y.W.; Formal Analysis, Y.W.; Investigation, Y.W.; Resources, J.Z.; Writing—Review and Editing, Y.W.; Supervision, J.Z.; Project Administration, Y.W.; Funding Acquisition, Y.W.

Funding: This research was funded by China Scholarship Council (CSC No. 201808610034).

Conflicts of Interest: The authors declare no conflict of interest. 


\section{References}

1. Huczkoa, A.; Kurcza, M.; Dabrowskaa, A.; Baranowskia, P.; Bhattaraib, A.; Gierlotkac, S. Self-propagating high-temperature synthesis (SHS) of crystalline nanomaterials. J. Cryst. Growth 2014, 401, 469-473. [CrossRef]

2. Gaggero, L.; Ferretti, M. The self-sustained high temperature synthesis (SHS) technology as novel approach in the management of asbestos waste. J. Environ. Manag. 2018, 216, 246-256. [CrossRef] [PubMed]

3. Lagos, M.A.; Agote, I.; Atxaga, G.; Adarraga, O.; Pambaguian, L. Fabrication and characterisation of titanium matrix composites obtained using a combination of self propagating high temperature synthesis and spark plasma sintering. Mater. Sci. Eng. A 2016, 655, 44-49. [CrossRef]

4. Hajalilou, A.; Hashim, M.; Ebrahimi-Kahizsangi, R.; Ismail, I.; Sarami, N. Synthesis of titanium carbide and $\mathrm{TiC}-\mathrm{SiO} 2$ nanocomposite powder using rutile and $\mathrm{Si}$ by mechanically activated sintering. Adv. Powder Technol. 2014, 25, 1094-1102. [CrossRef]

5. Yang, S.; Xiao, G.; Ding, D.; Ren, Y.; Lv, L.; Yang, P. Dissolution-precipitation mechanism of combustion synthesis of calcium aluminate. Ceram. Int. 2017, 43, 15918-15926. [CrossRef]

6. Yang, S.; Xiao, G.; Ding, D.; Ren, Y.; Lv, L.; Yang, P.; Gao, J. Solid-phase combustion synthesis of calcium aluminate with $\mathrm{CaAl}_{2} \mathrm{O}_{4}$, nanofiber structures. Ceram. Int. 2018, 44, 6186-6191. [CrossRef]

7. Oghenevweta, J.E.; Wexler, D.; Calka, A. Study of reaction sequences during MSR synthesis of TiC by controlled ball milling of titanium and graphite. Mater. Charact. 2018, 140, 299-311. [CrossRef]

8. Vasanthakumar, K.; Bakshi, S.R. Effect of C/Ti ratio on densification, microstructure and mechanical properties of TiCx prepared by reactive spark plasma sintering. Ceram. Int. 2018, 44, 484-494. [CrossRef]

9. Akhlaghi, M.; Tayebifard, S.A.; Salahi, E.; Asl, M.S.; Schmidt, G. Self-propagating high-temperature synthesis of $\mathrm{Ti}_{3} \mathrm{AlC}_{2}$ max phase from mechanically-activated $\mathrm{Ti} / \mathrm{Al} /$ graphite powder mixture. Ceram. Int. 2018, 44, 9671-9678. [CrossRef]

10. Martínez-Martínez, D.; Sánchez-López, J.C. Determination of the thickness of the embedding phase in 0d nanocomposites. Appl. Surf. Sci. 2017, 421, 179-184. [CrossRef]

11. Thomas, T.; Bowen, C.R. Effect of particle size on the formation of $\mathrm{Ti}_{2} \mathrm{AlC}$ using combustion synthesis. Ceram. Int. 2016, 42, 4150-4157. [CrossRef]

12. Sadeghi, N.; Aghajani, H.; Akbarpour, M.R. Microstructure and tribological properties of in-situ TiC-C/Cu nanocomposites synthesized using different carbon sources (graphite, carbon nanotube and graphene) in the Cu-Ti-C system. Ceram. Int. 2018, 44, 22059-22067. [CrossRef]

13. Ramos, J.P.; Stora, T.; Senos, A.M.R.; Bowen, P. Thermal stability of nanometric TiC-carbon composites: effects of carbon. J. Eur. Ceram. Soc. 2018, 38, 4882-4891. [CrossRef]

14. Wang, Y.C.; Zhao, J.P. Benign design and the evaluation of pyrolysis kinetics of polyester resin based intumescent system comprising of alkali-activated silica fume. Prog. Org. Coat. 2018, 122, 30-37. [CrossRef]

15. Wang, Y.C.; Zhao, J.P. Comparative study on flame retardancy of silica fume-based geopolymer activated by different activators. J. Alloys Compd. 2018, 743, 108-114. [CrossRef]

16. Oikawa, K.; Toyota, K.; Sakatani, S.; Hayashi, Y.; Takizawa, H. Facile synthesis and thermal properties of waterglass-based silica xerogel. Ceram. Int. 2019, 45, 4201-4207. [CrossRef]

17. Ahmed, Y.M.Z.; Zaki, Z.I.; Besisa, D.H.A.; Amin, A.M.M.; Bordia, R.K. Effect of zirconia and iron on the mechanical properties of $\mathrm{Al}_{2} \mathrm{O}_{3} / \mathrm{TiC}$ composites processed using combined self-propagating synthesis and direct consolidation technique. Mater. Sci. Eng. A 2017, 696, 182-189. [CrossRef]

18. Dhyani, V.; Bhaskar, T. A comprehensive review on the pyrolysis of lignocellulosic biomass. Renew. Energy 2018, B129, 695-716. [CrossRef]

19. Zhang, J.; Yan, Y.; Hu, Z. Preparation and characterization of foamed concrete with Ti-extracted residues and red gypsum. Constr. Build. Mater. 2018, 171, 109-119. [CrossRef]

20. Dyjak, S.; Norek, M.; Polański, M.; Cudziło, S.; Bystrzycki, J. A simple method of synthesis and surface purification of titanium carbide powder. Int. J. Refract. Met. Hard Mater 2013, 38, 87-91. [CrossRef]

21. Li, M.; Mu, B. Effect of different dimensional carbon materials on the properties and application of phase change materials: A review. Appl. Energy 2019, 242, 695-715. [CrossRef]

22. Rubin, A.E.; Ma, C. Meteoritic minerals and their origins. Chem. Erde 2017, 77, 325-385. [CrossRef]

23. Boutefnouchet, H.; Curfs, C.; Triki, A.; Boutefnouchet, A.; Vrel, D. Self-propagating high-temperature synthesis mechanisms within the Ti-C-Ni system: A time resolved x-ray diffraction study. Powder Technol. 2012, 217, 443-450. [CrossRef] 
24. Liu, G.; Yang, Z.; Lia, J.; He, G.; Chen, Y.; Chen, K.; Fan, D. Reaction path in formation of Ti1-xWxC solid solution by combustion synthesis. Ceram. Int. 2018, 44, 6127-6136. [CrossRef]

25. Ahmed, Y.M.Z.; Zaki, Z.I.; Bordia, R.K.; Besisa, D.H.A.; Amin, A.M.M. Simultaneous synthesis and sintering of $\mathrm{TiC} / \mathrm{Al}_{2} \mathrm{O}_{3}$, composite via self-propagating synthesis with direct consolidation technique. Ceram. Int. 2016, 42, 16589-16597. [CrossRef]

26. Zhu, X.; He, Q.; Hu, Y.; Huang, R.; Shao, N.; Gao, Y. A comparative study of structure, thermal degradation, and combustion behavior of starch from different plant sources. J. Therm. Anal. Calorim. 2018, 132, 1-9. [CrossRef]

27. Yang, Y.F.; Mu, D.K.; Jiang, Q.C. A simple route to fabricate TiC-TiB $/ 2$ Ni composite via thermal explosion reaction assisted with external pressure in air. Mater. Chem. Phys. 2014, 143, 480-485. [CrossRef]

28. Sharifitabar, M.; Khaki, J.V.; Sabzevar, M.H. Formation mechanism of $\mathrm{TiC}-\mathrm{Al}_{2} \mathrm{O}_{3}-\mathrm{Fe}_{3} \mathrm{Al}$ composites during self-propagating high-temperature synthesis of $\mathrm{TiO}_{2}-\mathrm{Al}-\mathrm{C}-\mathrm{Fe}$ system. Ceram. Int. 2016, 42, 12361-12370. [CrossRef]

29. Rahimi-Vahedi, A.; Adeli, M.; Saghafian, H. Formation of Fe-TiC composite clad layers on steel using the combustion synthesis process. Surf. Coat. Technol. 2018, 347, 217-224. [CrossRef]

30. Zarezadeh-Mehrizi, M.; Beygi, R.; Eisaabadi, G.; Velashjerdi, M.; Nematzadeh, F. Mechanically activated combustion synthesis of $\mathrm{Ti}_{3} \mathrm{AlC}_{2} / \mathrm{Al}_{2} \mathrm{O}_{3}$ nanocomposite from $\mathrm{TiO}_{2} / \mathrm{Al} / \mathrm{C}$ powder mixtures. Adv. Powder Technol. 2019, 30, 311-316. [CrossRef]

31. Jam, A.; Nikzad, L.; Razavi, M. TiC-based cermet prepared by high-energy ball-milling and reactive spark plasma sintering. Ceram. Int. 2017, 43, 2448-2455. [CrossRef]

32. Sundaram, D.; Yang, V.; Yetter, R.A. Metal-based nanoenergetic materials: Synthesis, properties, and applications. Prog. Energy Combust. Sci. 2017, 61, 293-365. [CrossRef]

33. Liu, Z.; Rakita, M.; Xu, W.; Wang, X.; Han, Q. Ultrasound assisted combustion synthesis of TiC in Al-Ti-C system. Ultrason. Sonochem. 2015, 27, 631-637. [CrossRef] [PubMed]

34. Findenig, G.; Buchegger, C.; Lengauer, W.; Veitsch, C.; Demoly, A. Investigation of the main influencing parameters on the degassing behavior of titanium carbonitrides using mass spectrometry. Int. J. Refract. Met. Hard Mater. 2017, 63, 38-46. [CrossRef]

(C) 2019 by the authors. Licensee MDPI, Basel, Switzerland. This article is an open access article distributed under the terms and conditions of the Creative Commons Attribution (CC BY) license (http://creativecommons.org/licenses/by/4.0/). 